3. The compressibility of indium at $25^{\circ}$ over the range 10o-500 megabars was found to be 0.0000027 , or about $2 / 3$ that of mercury.

cambrtoge, Mass.

[Contribution from the Rasearch Laboratory of Physical, Chemistry of ithe MassachusetTs Institute of TechnologX. No. 1 I7.]

\title{
ON THE ESTABLISHING OF THE ABSOLUTE TEMPERATURE SCALE.
}

By Fraderick G. KEYES.

Received September 29, 1919.

A new equation of state was published ${ }^{1}$ by the author, in $19 \mathrm{r} 7$, based on an attempt to use the atom essentially as conceived by Bohr. The simplest form of the equation is that which would be valid for a system of one type of molecules, which is to say, substantially completely unassociated. The equation is as follows where $p$ is the pressure, $v$ the volume and $T$ the temperature on the absolute scale,

$$
p=\frac{R T}{v-\delta}-\frac{A}{(v-l)^{2}} .
$$

In this equation $\delta$ is a function of the volume for polyatomic molecules and a constant for monatomic gases. Since, however, $\delta$ is equal to $\beta e^{-\alpha / v}$, where $\beta$ and $\alpha$ are constants, the term $\delta$ reduces to $\beta$ at large volumes.

In the paper referred to above the fundamental difference in the constant $\delta$ corresponding to van der Waals' $(b)$ constant was predicted for a monatomic system as compared to a diatomic system of molecules. Argon and atmospheric nitrogen were chosen as examples, to test the prediction derived from the physical basis used to obtain the equation, the data for the former gas being due to Onnes. For the latter gas, data due to Amagat was employed. The constant $\delta$ was found to be constant in the case of argon and a function of the volume for atmospheric nitrogen. The agreement of the calculated pressures with the pressures recorded by Amagat for atmospheric nitrogen at temperatures from $0^{\circ}$ to $200^{\circ}$ is so close even up to $1000 \mathrm{~atm}$. that it is interesting to investigate what comes out of the application of the atmospheric nitrogen equation to the problem of establishing the absolute temperature scale.

The usual mode of computing the corrections which a gas temperature scale requires has involved the use of Joule-Thomson data for the particular gas used. E. Buckingham reviewing the available data in 1907 completed an investigation which leaves nothing to be desired as regards completeness and skill. Recently more precise data has been supplied by I. G. Hoxton, but the temperature range has not yet been extended sufficiently to affect materially the conclusions reached by Buckingham.

1 Proc. Nat. Acad. Sci., 3, 323 (r917). 
Corrections for the different gas thermometers as well as the position of the ice point on the absolute scale have also been computed by Berthelot by means of an empirical relation involving the critical constants used to modify the equation of van der Waals. The results arrived at are not in general very different from the conclusions reached by Buckingham in his investigation.

\section{TABLF $I$.}

Atmospheric Nitrogen Equation of State. ${ }^{a}$

\begin{tabular}{|c|c|c|c|c|}
\hline \multicolumn{5}{|c|}{ Atmospheric Nitrogen Equation of State. ${ }^{a}$} \\
\hline & \multicolumn{4}{|c|}{ Pressures in Atmospheres of $760 \mathrm{~mm}$. Volumes in cc. per $\mathrm{g}$. } \\
\hline V. & $l=00^{\circ}$. & $16.03^{\circ}$. & $99.45^{\circ}$. & $199.5^{\circ}$. \\
\hline \multirow[t]{2}{*}{$5 \cdot 354$} & I 49.8 & 161.8 & $225 \cdot 4$ & 299.7 Computed pressure by equation \\
\hline & 150.0 & 162.0 & 225.0 & 299.0 Observed pressure by Amagat \\
\hline \multirow[t]{2}{*}{4.50} & I 99.8 & $2 \mathrm{I} 7.2$ & 306.6 & 4I4. 0 Computed pressure by equation \\
\hline & $200 \cdot 0$ & 217.0 & 307.0 & 414.o Observed pressure by Amagat \\
\hline \multirow[t]{2}{*}{3.46} & 250.4 & $273 . I$ & $390 \cdot 3$ & 53 I.3 Computed pressure by equation \\
\hline & 250.0 & 273.0 & 392.0 & 530.o Observed pressure by Amagat \\
\hline \multirow[t]{2}{*}{3.024} & 299.7 & 327.6 & 472,4 & 646.4 Computed pressure by equation \\
\hline & 300.0 & 328.0 & 474.0 & 644.o Observed pressure by Amagat \\
\hline \multirow[t]{2}{*}{2.729} & $347 \cdot 7$ & $3^{81} \mathrm{I} . \mathrm{I}$ & 552.9 & 759.5 Computed pressure by equation \\
\hline & 350.0 & 383.0 & 556.0 & 758.0 Observed pressure by Amagat \\
\hline \multirow[t]{2}{*}{2.5 II } & 396.0 & $434 \cdot 4$ & 632.8 & 870.8 Computed pressure by equation \\
\hline & 400.0 & 439.0 & 637.0 & 869.0 Observed pressure by Amagat \\
\hline
\end{tabular}

a The volume of one gram at one atm. as determined by experiment is 795.62 cc. This volume substituted in the equation of state gives $1.0004 \mathrm{~atm}$. instead of 1.0000 atm.

$$
\begin{gathered}
p=\frac{2.9138}{v-\delta} T-\frac{1587.2}{(v-0.007)^{2}} \\
\log _{10} \delta=0.2200-\frac{0.284}{V} \text { or } \delta=1.66 e^{-\frac{0.653}{v} .}
\end{gathered}
$$

Apparent mol. atmospheric nitrogen assumed 28.163

$\mathbf{1 . 6 6 \%}$ argon by weight

$98.34 \%$ nitrogen by weight

The constants of the equation used for atmospheric nitrogen were, as has been stated, taken from the data of Amagat between about I50 atm. and $1000 \mathrm{~atm}$. at $0^{\circ}$ to $200^{\circ}$. The differences between the computed and observed pressures, first and second horizontal rows, respectively, Table I, it will be observed nowhere exceed the probable error of measurement. It is evident that the mathematical form of the equation for this gaseous system is such that at constant volume the pressure is a linear function of the temperature.

The data for all the gases for which Amagat gives data may in fact be accurately represented by the same mathematical form of equation and since at these comparatively high pressures the isometrics appear to be linear with so great a degree of approximation, at the low pressures employed in gas thermometry the exactness of the linear increase of pressure with tem- 
perature must be very great. It follows from this, that the constant volume gas thermometer reads directly on the absolute temperature scale and therefore requires no correction. This was the conclusion reached by Regnault from a comparison of constant volume thermometers filled with different gases and employed at different initial or ice-point pressures. The doubt regarding the matter appears to rest largely upon certain measurements of the mean constant volume expansion coefficients at intervals between $0^{\circ}$ and $100^{\circ}$ determined by Chappuis. These coefficients showed a variation greater than the assumed errors of observation, but I have always been puzzled to understand how Chappuis picked off any desired interval with sufficient exactness between the freezing and boiling points of water. It was actually done by means of mercury thermometers, but a very minute error in locating the absolute temperature within the interval $0^{\circ}$ to $100^{\circ}$ would easily account for the variation of the coefficients found. The most exact method of deciding whether any given constant volume gas thermometer requires correction to reduce its readings to the absolute scale would certainly appear to resolve itself into determining whether the isometrics at high pressures are linear functions of the temperature or not.

Of course this procedure, it may be objected, assumes that a constant volume of gas can be carried from one point on the absolute scale to successive temperatures also on the absolute scale. The consideration, however, to be emphasized is, that if pressures from 100 to $1000 \mathrm{~atm}$. for constant volumes of gas increase in a substantially linear manner with temperature as given by the low pressure constant volume gas thermometer; then at the low pressures always employed in constant volume gas thermometry the straight line isometrics must be sufficiently exact to warrant the assumption that the thermometer readings really lie on the absolute scale.

Besides atmospheric nitrogen, air, oxygen, hydrogen and helium isometrics appear to show so exactly a linear increase of pressure with temperature increase at high pressure that the further consequences of assuming that the indications of the constant volume gas thermometer readings employing the latter gases also lie on the absolute scale is perhaps worth presenting. ${ }^{1}$

1 In considering the data given by the various investigators who have occupied themselves with gas thermometers, it is difficult to avoid the conclusion that adsorption of the gas on the thermometer walls may have had much to do with a great many of the discordant results presented in the literature. Eumorfopoulos, for example, repeatedly obtained too high a nitrogen expansion coefficient until he had heated the quartz thermometer bulb to a high temperature in vacuum several times. It is because of the adsorptive effect of gases in gas thermometry that metal thermometer bulbs offer a great advantage as compared with glass, porcelain or even quartz. 
TABLE II.

Constant Volume Gas Thermometer.

Observer.

Chappuis

Chappuis

Chappuis

Chappuis

Day and Clement

Day and Clement

Day and Clement

Day and Clement

Holborn and Henning

Holborn and Henning

Holborn and Henning

Onres and Bondin

Chappuis

Travers, Senter and Jaquerod

Holborn and Henning

Holborn and Henning

\begin{tabular}{|c|c|c|}
\hline $\begin{array}{l}\text { po. } \\
\text { Nitrogen. }\end{array}$ & - $a / v$ its, $0^{\circ}$ to $100^{\circ}$. & $T_{0}$ calculated. \\
\hline 528.8 & $3.668 \mathrm{II} \mathrm{Pt}$ & 273.094 \\
\hline $534 \cdot 3$ & $3.66846 \mathrm{Pt}$ & 273.072 \\
\hline 793.5 & $3.67180 \mathrm{Pt}$ & $273 \cdot 0.57$ \\
\hline 995.9 & $3.67466 \mathrm{Pt}$ & 273.018 \\
\hline $3 I_{4} .0$ & 3.6650 Pt-Ir & $273 \cdot 133$ \\
\hline 550.0 & 3.6680 Pt-Ir & 273.128 \\
\hline 744.0 & $3.670 \quad \mathrm{Pt}-\mathrm{Ir}$ & $273 \cdot 147$ \\
\hline 985,0 & 3.673 & $273 \cdot 139$ \\
\hline 620.6 & 3.6684 Quartz & 273.153 \\
\hline $63 I .3$ & $3.6705-59^{\text {III }}$ Glass & 273.007 \\
\hline 62 I.3 & $3.6702-59^{\text {III }}$ Glass & 273.022 \\
\hline \multicolumn{3}{|l|}{ Aydrogen } \\
\hline 1100.0 & 3.6627 Glass & $273 \cdot 548$ \\
\hline 1000.0 & $3: 66256 \mathrm{Pt}$ & $273 \cdot 147$ \\
\hline 700.0 & 3.6626 Quartz & 393.110 \\
\hline 623.0 & $3.6625-59^{\text {III }}$ Glass & 273.112 \\
\hline \multicolumn{3}{|l|}{ Helium } \\
\hline 614.0 & $3.6618-59^{\mathrm{III}}$ Glass & 273 . II 3 \\
\hline
\end{tabular}

Constant Pressure Gas Thermometer.

$\begin{array}{clll}100.0 & 3.6722 & \text { Pt } & 273.05 \\ 1387.0 & 3.676 & \text { Pt } & 273.01 \\ 760.0 & 3.667 \text { Glass } & 273.05 \\ 395.0 & 3.6656 \text { Quartz } & 273.130 \\ 415.0 & 3.66587 \text { Quartz } & 273.126 \\ 792.0 & 3.67005 \text { Quartz } & 273.123 \\ 784.0 & 3.67019 \text { Quartz } & 273.106 \\ 757.0 & 3.66991 \text { Quartz } & 273.106 \\ \text { Hydrogen } & \text { Hydrogen } & \\ \text { I000.0 } & 3.6600 & 273.115 \\ 760.0 & 3.6610 & 273.067\end{array}$

Chapptis

Chappuis

Regnault

Eutuorfopoulos

Eumorfopoulos

Eumorfopoulos

Eumorfopoulos

Eurnorfopoulos

Eurnorfopoulos

Chappuis

Richards, Marks and Witlzowski
273.067

Assuming then that the readings of the constant volume nitrogen thermometer lie on the absolute scale, the corrections which would follow from applying the equation of state given for atmospheric nitrogen to the constant pressure themometer will be given and also the position of the ice point on the absolute temperature scale as computed by means of the equations for the several other gases, using for this purpose the mean constant volume and constant pressure $0^{\circ}$ to $100^{\circ}$ expansion coefficients.

The correction equation, details of which are to be given in a later more complete paper, for the nitrogen constant pressure thermometer, is

$$
t_{a}-t=5.74 \times 10^{-3} t-3 \cdot 3^{-3} \frac{(2+\epsilon t)}{(1+\epsilon t)} t,
$$


where the pressure is $1000 \mathrm{~mm}$. and $t_{a}$ the reading on the absolute scale, $t$ that of the gas scale and $\epsilon$ has a value of 0.00366 . The mean coefficient equation for $\epsilon_{2}^{a}$ for nitrogen between $0^{\circ}$ and $100^{\circ}$ is, where $\epsilon=\mathrm{I} / 273.135=$ 0.0036612

$$
\epsilon_{p}^{a}=\epsilon+1.098 \times 10^{-8} p-4.24 \times 10^{-14} p^{2}
$$

where the pressure is expressed in mm.

The equation for $\epsilon_{\nu}^{\sigma}$, the coefficient ${ }^{1}$ for the constant volume nitrogen thermometer, follows very simply from the nitrogen equation of state and is $\epsilon_{v}^{a}=0.00366 \mathrm{I} 2+\mathrm{r} .0207 \times 10^{-8} p_{0}$, where $p_{0}$ is measured in mm.

Table II gives the ice point on the absolute scale as calculated for each of the kinds of expansion coefficient. The constant volume data of Day and Clement are by far the most reliable and give the mean value 273.137. The work of Eumorfopoulos, wherein a quartz bulb was used, is quite reliable and gives the mean 273.II8. If these two values are averaged with the Onnes hydrogen, and the Holborn and Henning hydrogen and helium values, the mean comes out 273.126. The coefficients obtained by Day and Clement, however, for the measurement of which a platinum iridium bulb was employed whose coefficient of expansion was carefully investigated, would appear most reliable. The mean value 273.137 for the ice-point is therefore believed to be nearly correct. The number 273.14 may be accepted. The number decided upon by Buckingham was 273.13 .

TABLA III.

Sulfur Boiling Point.

Constant volume thermometer.

\begin{tabular}{|c|c|c|c|c|c|}
\hline onstant volum & me thermom & 20 & stant pressur & U & neter. \\
\hline Observer. & $\begin{array}{l}\text { t. } \\
\text { Nitrogen gas } \\
\text { thermometer. }\end{array}$ & Observer. & $\begin{array}{l}\text { l. } \\
\text { Nitrogen gas } \\
\text { thermometer. }\end{array}$ & & $\begin{array}{l}\text { t. } \\
\text { Abs. cent } \\
\text { temp. }\end{array}$ \\
\hline & & Eumorfopoulos & $\begin{array}{l}444.392 \\
p_{0}=395\end{array}$ & $+0 . x 97$ & 444.59 \\
\hline $\begin{array}{l}\text { Chappuis and } \\
\text { Harker }\end{array}$ & $\begin{array}{l}444.70 \\
\text { Coef. Exp. of } \\
\text { porcelain un- } \\
\text { certain }\end{array}$ & $\begin{array}{l}\text { Eumorfopoulos } \\
\text { Eumorfopoulos }\end{array}$ & $\begin{array}{l}444 \cdot 356 \\
p_{0}=415\end{array}$ & to.208 & 444.56 \\
\hline $\begin{array}{l}\text { Reichsanstalt, Wiebe } \\
\text { \& Bötcher }\end{array}$ & 444.50 & Eumorfopoulos & $\begin{array}{l}444 \cdot 125 \\
p_{0}=757\end{array}$ & +0.378 & 444.50 \\
\hline $\begin{array}{l}\text { Holborn } \\
\text { Extrap. Pt. Res. }\end{array}$ & 444.55 & Eumorfopoulos & $\begin{array}{l}444 \cdot \mathbf{1} 40 \\
p_{0}=784\end{array}$ & +0.392 & 444.53 \\
\hline Holborn and Henning & g $444 \cdot 5^{I}$ & Etumorfopoulos & $\begin{array}{l}444 . \mathrm{I} 25 \\
p_{0}=892\end{array}$ & +0.396 & $444 \cdot 5^{2}$ \\
\hline Mean, last 3 & 444.52 & Eumorfopoulos & & Mean & $444 \cdot 54$ \\
\hline
\end{tabular}

The sulfur boiling-point temperature has not shown agreement as measured on the constant volume and constant pressure gas thermom-

${ }^{1}$ The superscript $a$ in $\epsilon_{y}^{a}$ refers to the actual coefficient at constant pressure, denoted by the subscript as distinguished from the ideal coefficient $\epsilon$. The $\epsilon_{v}^{a}$, refers similarly to the expansion coefficient at constant volume of an actual gas. 
eters. The constant pressure thermometer work at this fixed point suffered from the fact that a bulb of suitable material has only recently been employed. In the paper by Eumorfopoulos ${ }^{1}$ the sulfur point was measured at several different pressures by means of a quartz bulb Callendar gas thermometer. With the corrections appropriate to the scale these various temperatures of boiling sulfur have been corrected by means of the correction equation given above. The corrected values appear in Table III, together with the values of the sulfur boiling point obtained recently with the constant volume thermometer. A small table (Table IV) of the corrections computed from $0^{\circ}$ to $r 000^{\circ}$ is also given and values obtained by $\mathbb{E}$. Buckingham through the Joule-Thompson numbers are listed for comparison.

\section{TABLE IV.}

Constant Pressure Nitrogen Thermometer.

Corrections computed by the equation of state compared with those computed from Joule-Thompson coefficients. $p=1000 \mathrm{~mm}$.

$\begin{array}{rcc}T . & \left(i_{a}-t\right) \text {. Computed } & \begin{array}{c}\left(t_{a}-t\right) . \\ \text { equation of state. }\end{array} \\ 20 & -0.0123 & -0.0137 \\ 40 & -0.0184 & -0.0203 \\ 60 & -0.0176 & -0.0198 \\ 80 & -0.0009 & -0.0129 \\ 200 & +0.105 & +0.105 \\ 444 & +0.500 & +0.502 \\ 600 & +0.84 & +0.827 \\ 800 & +1.28 & +1.262 \\ 1000 & +1.72 & +1.706\end{array}$

Attention is called to the close agreement of the scale corrections obtained by such diverse methods. Of course if the linear increase of the pressure with temperature is as exact as it appears to be in the case of nitrogen and argon, hydrogen and helium at higher temperatures, for the low pressures employed in thermometry the constant volume thermometer would certainly need no correction.

The sulfur boiling point mean corrected to the absolute scale as indicated is 444.54 for the constant pressure gas thermometer whereas the constant volume thermometer mean of the recent work is 444.52 .

Cambridgh, Mass.

1 Proc. Roy. Soc. (London), 90A, I89 (1914). 